\title{
Eros e Narciso: A ebulição das forças anímicas
}

\author{
Eros and Narciso: Ebulition of the animic forces
}

Fernanda Menin ${ }^{[0]}$, Lilian Loureiro ${ }^{[b]}$, Milena Neri Guarnieri ${ }^{[c]}$, Noely Montes Moraes ${ }^{[d]}$

\footnotetext{
${ }^{[a]}$ Psicóloga clínica, psicoterapeuta e pesquisadora do grupo SEJA, São Paulo, SP- Brasil, e-mail: femenin@ig.com.br

${ }^{[b]}$ Mestre em Psicologia Clínica pela Pontifícia Universidade Católica de São Paulo (PUC-SP), psicoterapeuta, pesquisadora do grupo SEJA, São Paulo, SP- Brasil, e-mail: lilianloureiro@uol.com.br

${ }^{[c]}$ Psicóloga clínica, pós-graduanda pela Pontifícia Universidade Católica de São Paulo (COGEAE) PUC-SP), pesquisadora do grupo SEJA, São Paulo, SP- Brasil, e-mail: milguarnieri@hotmail.com

${ }^{[d]}$ Professora titular da Pontifícia Universidade Católica de São Paulo (PUC-SP), vice-diretora da Clínica Psicológica Anna Maria Poppovic, psicoterapeuta e coordenadora do grupo SEJA, São Paulo, SP- Brasil, e-mail: noelymontes@yahoo.com.br
}

Recebido: 06/10/2009 Received: 10/06/2009

Aprovado: 10/11/2009 Approved: 11/10/2009

\section{Resumo}

Do ponto de vista psicodinâmico, o narcisismo expressa uma inflação egoica - situação que impede a consciência de reconhecer a alteridade. Algumas relações e situações sociais espelham essa condição, constituindo-se de projeções mútuas em que a preservação da imagem (persona) exige a exclusão de aspectos incompatíveis, depositando-os no Outro.

Esta dinâmica impede a aproximação de Eros, pois não há o reconhecimento do Outro, a não ser como espelho. Não há quem discorde que nossa época apresenta alterações profundas no modo de se vivenciar as experiências humanas fundamentais. Valores, costumes, relacionamentos, tudo que vivemos parece irreconhecível para alguém do começo do século XX. Neste trabalho, pretendemos apontar a função da dinâmica narcísica como etapa necessária ao processo de individuação, pois tem por finalidade permitir o reconhecimento e posterior integração de aspectos negligenciados pela persona. Utilizando o mito de Narciso, a partir da amplificação simbólica, refletimos a respeito das possibilidades criativas trazidas pelo sacrifício/ transformação/morte de Narciso: o abandono do contato superficial com a imagem refletida conduz à vivência da identidade profunda representada pelo enraizamento no Self (a transformação em flor), abrindo espaço para a aproximação de Eros. Buscamos traçar paralelos desse caminho transformador/criativo com a condição contemporânea, arriscando vislumbrar saídas para o indivíduo e para o coletivo.

Palavras-chave: Narcisismo. Individuação. Contemporaneidade. Alteridade. Relação amorosa.

\section{Abstract}

From the psychodynamic perspective, narcissism expresses an egoic inflation - a situation that prevents conscience to recognize the otherness. Some relationships and social situations reflect this condition, consisting of mutual projections where the preservation of the image (persona) requires the exclusion of incompatible features, depositing them in the Other. This dynamics prevents the approach of Eros, because there is no recognition of the Other, unless as a mirror. There's no one who disagrees that our time has shown profound changes in the way of living the fundamental human experiences. Values, ways of doing, relationships, everything that we live now is hard to be recognized by anyone from the early twentieth century. In this work, we intend to show the role of narcissistic dynamics as a necessary step in the individuation process, 
as it is intended to enable the recognition and further integration of neglected aspects by one's persona. Using the myth of Narcissus, from a symbolic amplification, we reflected on the creative possibilities brought by the sacrifice/transformation/death of Narcissus: the abandonment of superficial contact with the mirror image leads to the experience of profound identity represented by the deepening of roots in the Self (the transformation into a flower), making room for Eros' approach. We seek to draw parallels between this transformer/creative process with the contemporary condition, trying to find a scape way for the individual and for the collective.

Keywords: Narcissism. Individuation. Contemporary. Otherness. Love relationship.

\section{Introdução}

\section{Pós-modernidade e relacionamentos}

De acordo com Lipovetsky (2004b), a época atual se define como hipermodernidade. Segundo ele, a hipermodernidade se apresenta como uma época repleta de paradoxos: o tempo acelerado $\mathrm{X}$ - a necessidade da redescoberta do tempo; a preocupação com a qualidade de vida, o extremo cuidado com o corpo. As relações reais de proximidade cedem lugar aos intercâmbios virtuais, à sensualização extrema, embora o indivíduo hipermoderno seja igualmente prudente, afetivo e relacional: a aceleração dos ritmos não aboliu a sensibilidade em relação ao outro, nem as aspirações a uma vida equilibrada e sentimental.

0 foco está no presente, embora, segundo o autor, o passado seja revisitado. Há a desvalorização de formas de espera e lentidão. Desenvolve-se o domínio técnico acerca do espaço-tempo, mas declinam-se as forças interiores do indivíduo. Quanto menos as normas coletivas regem-no nos detalhes, mais o indivíduo se mostra tendencialmente fraco e desestabilizado. Presenciamos a fragilização das personalidades e a ocorrência de doenças psicossomáticas, distúrbios compulsivos, depressão, ansiedades, tentativas de suicídio, sentimentos de insuficiência e autodepreciação.

Para Lipovetsky (2004a), essa desordem aparente promoverá uma nova organização: uma desordem organizadora.

Aratangy (2007) apresenta uma visão interessante acerca do tema. Segundo ela, no afã de viver intensamente o novo, há uma tendência em nossa cultura a não tolerar o contato com o desgaste e o envelhecimento, sequer dos objetos. A autora utiliza a seguinte metáfora para explicar as características do tempo atual: é como se estivéssemos nos deparando com um bufê que ostenta uma enorme fartura de opções e um conviva faminto dificilmente será capaz de compor uma refeição balanceada. A quantidade e variedade de ofertas dificultam a escolha. 0 único caminho para fazer escolhas adequadas, que garantam uma dieta equilibrada, é conhecer os próprios desejos e necessidades e ter algumas informações a respeito da composição dos vistosos quitutes.

A hipermodernidade é fértil no sentido de que a multiplicidade que criou pode nos auxiliar em novas descobertas, naquilo que podemos vir a ser, no desenvolvimento de nossas potencialidades. Paradoxalmente, essa mesma multiplicidade é fonte de um maior número de frustrações. Lipovetsky (2007, p. 14) afirma: "A sociedade hipermoderna é propriamente aquela que multiplica ao infinito as ocasiões de experiência frustrante, ao mesmo tempo que deixa de proporcionar os antigos dispositivos "institucionalizados" para debelar esse mesmo mal".

No campo dos relacionamentos, nota-se pouca disposição a enfrentar situações desagradáveis, descartando-se a relação tão logo se perceba que ela não atende ao ideal almejado. A tolerância à frustração faz parte de um aprendizado a ser desenvolvido sem que haja desistência do encontro, pois teríamos como consequência um prejuízo tanto do nosso autoconhecimento, como da nossa capacidade criativa.

Não há quem discorde que nossa época apresenta alterações profundas no modo de se vivenciar as experiências humanas fundamentais.

Valores, costumes, relacionamentos, tudo que vivemos hoje, parece irreconhecível para alguém do começo do século XX.

Sai de cena o amor romântico, com seu inevitável estreitamento de foco da consciência no ser amado, como 
tão bem retrata Philip Roth (2001, p. 85), por meio de um personagem de seu livro $O$ Animal Agonizante:

A única obsessão que todo mundo quer ter: o 'amor'. As pessoas pensam que quando se apaixonam elas se completam? A união platônica das almas? Pois eu não concordo. Eu acho que você está completo antes de se apaixonar. E o efeito do amor é fracionar você. Antes você está inteiro, depois racha ao meio. (0 objeto amado) é um corpo estranho que se introduz na sua integridade, e que você passa anos tentando incorporar. Mas você só vai conseguir ficar inteiro depois que expelir esse corpo estranho. Ou bem você se livra dele ou bem você o incorpora, distorcendo a si próprio. E se você o fizer, você enlouquece.

Aquela tão proclamada divina loucura do amor, agora é vista com olhar desconfiado. Pior, qualificada como patologia mesmo.

Quando as formas culturais não mais confirmam os valores outrora atribuídos aos relacionamentos amorosos, a narrativa subjetiva se desorienta e vai em busca de novos apoios coletivos. Esse movimento dialético cria e atualiza os mitos estruturantes de cada época.

Buscando artigos que esclarecessem este ponto, encontramos dentre outros, Rios (2008, p. 423), no qual a autora afirma: "Na falta de referências culturais que legitimem a experiência com o Outro, como diferente e desejável, o ego tem a si mesmo como objeto de amor e de sustentação de sua identidade".

Apoiada em autores que se debruçaram no entendimento desses tempos, a autora situa o início da época contemporânea por volta da década de 1930 do século XX. Lipovetsky (2004b) denominou-a Época Hipermoderna.

Uma das características fortemente presente na nossa época é a necessária produção de sentido para a existência, que se faz de forma individual, na medida em que as grandes narrativas ideológicas fracassaram. Esta difícil tarefa existencial tornou-se o maior fardo psíquico, pois já não é possível ao homem valer-se de poderes divinos ou metafísicos para explicar o fracasso ou sucesso de sua vida, nem para ampará-lo nas vicissitudes.

A exigência de demonstrações constantes de felicidade em todas as áreas da vida, aliada à responsabilização exclusiva de buscá-la por si mesmo, sobrecarregam e inflam o ego.

Segundo Rios (2008, p. 423), "a cultura contemporânea, também chamada cultura narcísica, reproduz conceitos e práticas que não sustentam a alteridade e, constantemente, devolvem o sujeito para o miolo de si mesmo quando este procura referências fora de si, na experiência coletiva".

Em outro artigo consultado, Monti (2008) se refere à sociedade atual como tendo substituído a culpa e conflito, que caracterizaram o ethos cristão por dois mil anos, pelo que ele denomina de cultura do empreendimento e iniciativa.

Essa substituição desloca a angústia de culpa, castigo, reparação, para uma avaliação de desempenho, em que a angústia também se faz presente, mas sob a forma de deficit, de insuficiência perante às onipresentes expectativas que nunca serão alcançadas, por definição.

Outra ideia que perdeu seu valor foi a do sacrifício. Se, antes, a capacidade de suportar algo penoso era vista como virtude, hoje é vista como acomodação, covardia; não extrair o máximo de prazer da vida é encarado como incompetência!

0 grande perigo desse estado de coisas está no afrouxamento ético trazido pela substituição da culpa pela vergonha como limite ao exercício do prazer. A vergonha, mais primitiva em termos de desenvolvimento moral, como afirmava Piaget, só atua diante da possibilidade de ser surpreendido ou de ser concretamente penalizado.

Sem culpa, nem renúncia, a perversão torna-se uma possibilidade não tão absurda. Sem uma referência coletiva de consenso, a ética torna-se uma tarefa mais penosa para o ego, que deve definir solitariamente o "em nome do quê" sacrificar seu prazer imediato.

Bauman (2004) também decreta que a definição do amor como "até que a morte nos separe" está decididamente "fora de moda". A súbita abundância e a evidente disponibilidade de experiências amorosas podem alimentar, segundo ele, a convicção de que amar é uma habilidade que se pode adquirir, e que o domínio dessa habilidade aumenta com a prática. Esta maneira de se lidar com a questão amorosa resulta numa visão do amor como uma série de episódios intensos, curtos e impactantes.

Sem os valores do sacrifício e da renúncia, suportar doses de conflito e frustração para manter um relacionamento pode ser visto como inutilidade e perda de tempo e oportunidades.

Ao longo da história, diferentes formas de relacionamento foram consideradas legítimas, ainda que nem sempre reconhecidas juridicamente, como, por exemplo, a poligamia, o concubinato, os relacionamentos 
homossexuais e extraconjugais; mais recentemente, 0 "ficar", como ensaio para a vida amorosa e sexual e os relacionamentos mediados pela internet.

A busca de segurança e estabilidade como valores mais importantes do que paixão e prazer ainda tem seu público; a moça bonita e virgem que se casa com rapaz rico e promissor também é modelo; o prazer sem compromisso e o apego à liberdade, idem. Ou seja, o que nosso tempo trouxe não foi um modelo novo de relacionar-se, mas a convivência de todos os modelos, ou dito de outra forma, a ausência de um modelo consensual.

Neste trabalho, vamos nos concentrar em entender como a marca narcisista de nossa época toca os relacionamentos amorosos e tentar perceber nessa dinâmica psíquica, coletiva e individual, os elementos que permitam identificar seus efeitos em termos de desenvolvimento da consciência. Enquanto os trabalhos levantados qualificam o narcisismo apenas como quadro patológico cristalizado, acreditamos que a eclosão do narcisismo como dominante psíquica contemporânea se constitui como etapa necessária para a passagem do mito romântico amoroso para o mito de alteridade.

\section{Narcisismo: mito, transformações, amplificação, psicodinâmica}

O mito de Narciso reflete a história de amores impossíveis, imagens que enganam e, principalmente, de autoconhecimento e transformação. Esse aspecto é de extrema importância, uma vez que aponta um caminho, uma finalidade a ser atingida. Ficar apenas no aspecto egoico, individualista, egoísta de Narciso, é matar todo seu potencial inerente de transformação. Faz parte do processo de desenvolvimento nos ver nos olhos do outro. Ele é nosso espelho, imprescindível para consolidação do eu.

De acordo com Lipovetsky (2004a, p. 31):

Cada geração gosta de encontrar sua identidade em uma grande figura mitológica ou lendária, que reinterpreta em função dos problemas do momento: [...] Hoje em dia é Narciso que, aos olhos de considerável número de pesquisadores [...] simboliza os tempos atuais.

O mito ilustra as características e o potencial de transformação desta dinâmica. Relataremos brevemente algumas passagens do mito, segundo a ver- são de Ovídio, traduzida na obra de Schwartz-Salant (1995). 0 mito começa com as palavras do adivinho cego Tirésias que, ao ser interrogado pela mãe de Narciso, a ninfa Liríope, se a criança viveria muito, respondeu: "Se ele jamais se conhecer". Ao longo de sua vida, Narciso rejeitou todos os jovens e donzelas que desejaram seu amor, inclusive a ninfa Eco, condenada por Hera a apenas repetir as últimas frases daquilo que lhe é dito, pois a ninfa a mantinha entretida conversando para que esta não surpreendesse Zeus com as outras ninfas nas montanhas.

Assim seguiu, até que um dia uma jovem rejeitada por Narciso se dirige aos céus e suplica: "Pois que possa ele amar a si mesmo e não obter aquilo que ama!". A deusa Nêmesis atendeu a sua prece. Vale lembrar que a deusa Nêmesis representa a imagem de justiça que pune todos os excessos.

Narciso estava caçando e, exausto pelo calor, passa por uma clara fonte de límpida água prateada, cuja superfície perfeita jamais havia sido maculada por nenhum animal ou galho caído. Enquanto mata sua sede, vê sua imagem refletida na água e apaixona-se irremediavelmente por ela. Fascinado pela imagem, Narciso lamenta sua sorte - permanentemente separado de seu objeto de amor por uma tênue barreira de água. Ele passa todo o tempo contemplando a própria imagem, e não há alimento ou descanso que o afaste de lá. Assim, Narciso definha e morre, à beira da fonte, mas, em lugar de seu corpo, é encontrada uma flor, de centro amarelo e pétalas brancas.

O mito começa com a profecia de Tirésias, que diz a Liríope que Narciso só viverá enquanto não se conhecer. Isso deixa claro que a consciência, ou o autoconhecimento, acabarão com a vida de Narciso, ou seja, farão com que ele se transforme. Após se conhecer, não será mais possível Narciso continuar a existir como tal, o que denota a importância do autoconhecimento para a saída do estado narcísico. Além disso, Tirésias é um adivinho cego. Podemos pensar que Tirésias representaria o poder da introversão, o "olhar para dentro", uma vez que não lhe é possível olhar para fora. É exatamente o oposto da condição narcísica, que apenas olha para fora em busca de seu próprio reflexo no olhar dos outros, como Narciso encontrou na fonte, tão cristalina e imaculada que era um perfeito espelho.

Narciso rejeita todos os homens e mulheres que desejam o seu amor. Essa é a perfeita descrição do comportamento de não vinculação do perfil 
narcisista: a recusa em se relacionar. Isso não quer dizer que as pessoas que apresentam esse perfil não estabeleçam contatos com os demais, inclusive amorosos, mas que tais contatos fiquem restritos ao grau físico. Não são relações genuínas, pois, do ponto de vista psicológico, a definição de relação implica em dois indivíduos trocando. Estar na presença do outro, mas colocá-lo no lugar de plateia, de mero observador e "reflexor" da imensa beleza e talento pessoais não é se relacionar, segundo essa perspectiva. Inúmeras "relações" amorosas hoje em dia são estabelecidas nessas bases.

Após inúmeras rejeições, Narciso é condenado pela deusa Nêmesis a sofrer do mesmo vazio que provocava nas pessoas: a impossibilidade de ter o objeto de amor. Isso o coloca em situação análoga a de seus pretendentes rejeitados, e desencadeia a transformação. A fixação na própria imagem, que leva ao definhamento e à morte de Narciso, não é tão trágica quanto parece. Conforme Tirésias havia profetizado, uma vez que se conheceu ele teria que morrer, mas a morte de Narciso desencadeia sua transformação em flor.

Podemos perceber que, ao longo do mito, nos deparamos com dois Narcisos distintos. Aquele do início da história, representado por alguém que de tão centrado em si mesmo, se basta. Jovem duro e frio, comparado a uma estátua de mármore de tão impenetrável, que rejeita o envolvimento erótico com o outro. Para este Narciso o outro não existe, violentando Eros com esse perfil.

É este Narciso que encontramos descrito nos Transtornos de Personalidade Narcisista que, de acordo com o DSM IV (2002), é entendido como um padrão de grandiosidade, necessidade de admiração e falta de empatia, tendo atitudes arrogantes e insolentes. 0 indivíduo narcisista baseia-se na crença de ser especial e único, o que justificaria a expectativa irreal de receber um tratamento especialmente favorável ou obediência automática as suas expectativas, além de serem insensíveis, superficiais e antipáticos. Pessoas portadoras desse transtorno possuem uma autoestima bastante frágil, sentem medo de que suas falhas e imperfeições sejam reveladas. Assim, narcisista não é aquele que se ama demais, mas aquele que não se ama. Daí decorre a diferença fundamental entre narcisismo e autoestima.

De acordo com Schwartz-Salant (1995), do ponto de vista psicodinâmico, o perfil narcisista apresenta algumas características crônicas: carência de penetrabilidade (mantém distância), intolerância a críticas, baixa capacidade empática, orgulho por não precisar dos outros, falta de continuidade histórica, funcionamento Masculino e Feminino perturbado e potencial para formações arquetípicas positivas. Vamos desenvolvê-las a seguir.

A combinação dessas características, em maior ou menor grau, resulta na manifestação do comportamento de não vinculação e não reconhecimento do outro, que é colocado no lugar de espelho, ou plateia, o que impede as relações genuínas de troca.

Schwartz-Salant (1995) enfatiza que, especialmente na primeira infância, é fundamental que a criança seja espelhada pelos pais, e principalmente pela mãe, pois no primeiro estágio de desenvolvimento, o Self da criança está projetado na figura materna. Para o autor, a reflexão adequada trará posteriormente ao ego a experiência de estar conectado ao Self, condição fundamental para a saúde e integridade egoica. 0 que ocorre muitas vezes é o desejo dos pais de que a criança os reflita, o que é uma das situações que pode levar ao aprisionamento da consciência na dinâmica narcísica. Segundo Moore (1992), o narcisista busca, com grande esforço, encontrar a autoaceitação por meio de espelhos, o que se reflete como mecanismo de defesa.

É justamente o princípio de Eros que promove a transformação do jovem Narciso do início da história. Sua dificuldade com a alteridade, sua falta de sensibilidade em se colocar no lugar do outro, desperta a ira de todos e provocou sua maldição. A célebre maldição de Nêmesis foi sua salvação, seu ingresso para seu processo de transformação, sua metamorfose e a justificativa do porquê o mito de Narciso encontra-se no livro As Metamorfoses de Ovídio.

É a partir deste ponto do mito que o princípio de Eros se faz presente e a ebulição das forças anímicas começa a emergir: a água, por meio do fogo transforma-se em ar. Narciso, ao deparar-se com a própria imagem refletida no lago, apaixona-se. Num primeiro momento, não reconhece que é a própria imagem que vê. Leva um tempo até dar-se conta de que o que está vendo, é a si mesmo. A previsão de Tirésias se faz presente: num primeiro momento, ele não se reconheceu refletido, uma vez que não se conhecia, mas ele tem um insight e percebe que aquela bela imagem trata-se dele mesmo! O jovem frio, insensível e distante morre e sua transformação acontece, nesse ponto do conto ele passa a enxergar algo fora dele. Mesmo que seja ele, é visto e identificado como outro. 
O narcisismo é um quadro que traz em si a união de forças curadoras e destrutivas - há o impulso em direção à individuação e ao mesmo tempo em direção à fusão ego/Self, por isso, apesar de uma atitude externa de nãovinculação, é comum ocorrerem sonhos que apontam para o potencial de transformação, como afirma Schwartz-Salant (1995). Assim, as forças curadoras que habitam o indivíduo podem emergir a partir de uma relação profunda com o inconsciente e então o potencial daquele indivíduo de fato aparecerá. Neste sentido, podemos dizer que o narcisismo é o "vir-a-ser".

Conforme observamos também, sua morte desencadeia uma transformação. Torna-se uma flor, que simbolicamente representa o contato com o espírito e contém a capacidade de enraizamento. Muitas flores são mandalas, imagens que representam o Self. A transformação de Narciso em flor representa a saída do estado narcísico de consciência para um estado que permita o "enraizamento no Self" e, por conseguinte, a possibilidade de relação com a dimensão espiritual.

Para Capriotti (2005), é interessante notar que é pela primeira vez à beira da lagoa que Narciso reflete e descobre algo sobre si mesmo. Interessante, pois a autora enfatiza que é na água, no elemento de sua herança natal, uma vez que é filho de uma ninfa com o rio, que aquele Narciso duro e impenetrável pode recuperar sua umidade natural, transformando sua autoabsorção em um amável diálogo com o mundo. Moore (1992), complementa que o narcisismo é entendido como uma oportunidade da alma encontrar seus outros aspectos.

O narcisista desconhece quão profunda e interessante é sua natureza. Esforça-se muito em ser amado e não percebe que primeiro precisa amar a si mesmo como "outro" antes de ser amado, aquele outro refletido no olhar do adulto, extasiado com a criança. Para Schwartz-Salant (1995), o processo analítico favorece essa transformação. Segundo ele é importante que o analista ceda ao controle do "fique quieto e me escute". Tal negociação é o germe da transformação. Se negociado com sucesso, o analista pode passar a sentir uma maior empatia pelo analisado, o que facilita a penetração em camadas mais profundas da personalidade. Ainda existirá o controle, mas com o apelo do "fique comigo!, com meu íntimo, meu valor". Para o autor, essa mudança é impressionante, de alguém que era experimentado como enfadonho e superficial, emerge uma pessoa que reconhece o significado do termo espírito. Narciso só fica pronto para se amar quando aprende a amar aquele eu como objeto. Schwartz-Salant (1995, p. 121) traduz de forma poética, "Narciso só pode se transformar verdadeiramente quando transforma o espelho em janela, quando sai da autocentração e consegue enxergar o outro".

Uma das melhores formas de mostrarmos ao outro como ele é, talvez seja "ecoando" seus gestos, e de nos conhecermos, é prestar atenção em como os outros nos "ecoam". Estar em relação com o outro é uma necessidade arquetípica, ou seja, é própria da natureza humana a busca pelo encontro.

\section{Narcisismo, poder e relacionamentos}

Jung (1980) afirmava que o que se opõe ao amor é o poder. Ele explorou essa polaridade em diversos contextos, até mesmo para explicar as divergências teóricas entre Adler e Freud, atribuindo à primeira a predominância do instinto de poder, e à segunda, o de Eros. Relacionou-as ainda com as funções introvertida (poder) e extrovertida (Eros).

0 instinto de poder, segundo Jung (1980), revela uma tendência da libido de dirigir-se ao ego. Manifesta-se como necessidade de controle e autoafirmação. A dinâmica narcísica apresenta essa predominância do instinto de poder sobre o de Eros.

Carotenuto (1994) explora as implicações do abuso de poder nas relações como estratégia narcisista. 0 uso de poder se faria necessário para combater, negar ou exorcizar a temida imagem de ruína; a afirmação própria, para o narcisista, está estreitamente ligada ao fracasso de outra pessoa, afinal o poder não é exercido sobre objetos mas sim sobre pessoas. Desta maneira, estabelece-se o sistema de a pessoa narcisista exercer o poder sobre alguém versus alguém estar submetido ao seu poder.

Nas relações, o poder se exprime nas tentativas de cada um bloquear as potencialidades do outro, segundo Carotenuto (1994). O bloqueio das potencialidades impossibilita a criatividade que é a inimiga mortal e natural do poder. Da criatividade é emanada carga positiva, enquanto que o poder congela uma atmosfera negativa. Assim, a criatividade combate a rigidez, não necessitando do aprisionamento do outro, vive com autonomia e aceita a relação com seus semelhantes. 
A necessidade de plateia, para exercer a influência sobre o destino do outro, do ideal de verdade, do só poder existir manipulando os outros, fecha portas para o contato real com o outro e o mundo, não há encontro, relação, dos quais as verdades possíveis brotam e aparecem (dimensão dialógica).

Compreendemos que, para sentir-se vivo, para sair do nada e da morte, o homem deve criar, com as obras e com o pensamento. 0 poder liberta das necessidades, mas deste modo leva para a morte, porque a falta de desejo é morte. [...] Graças ao confronto com o desespero, e depois de ter dele saído, podemos tentar falar e fazer os outros participarem da nossa experiência (Carotenuto, 1994, p. 195).

Procuramos o poder quando sentimos insegurança. Quando encontramos e exercemos esse poder, propiciamos segurança a outras pessoas que se sentem indefesas sobre as mesmas necessidades do detentor do poder, ocasionando um "mecanismo diabólico", o qual separa, ilude, destrói, dá falsa percepção de libertação da necessidade e faz a parte parecer o todo.

Desta maneira, continua Carotenuto (1994), o real sentido de libertação advém de aceitarmos a possibilidade de sempre estarmos insatisfeitos. Aqueles que têm experiências de fracasso e insatisfação, pode-se dizer que são mais fortes simplesmente pelo fato de terem sentido necessidade de sair do conforto da zona de segurança e se lançado além das fronteiras do conhecido em direção ao mistério; afinal, nos momentos de maior dificuldade é que entramos em contato com nossa dimensão oculta. 0 insucesso, o fracasso têm como único árbitro a própria pessoa que experienciou a vivência, o que necessariamente obriga a ir em oposição à mediocridade, e sair do coletivo previsível e proposto. A experiência amorosa evocada por Eros produz exatamente tal exposição ao risco do fracasso, da perda e da dor, tão temidos pelo narcisista que, para evitá-los, desenvolve sofisticadas estratégias de controle.

Para Carotenuto (1994), dois caminhos nos são apresentados: a) o de maior facilidade: de estar sempre em harmonia, evitar o mal-estar e passear ao longo da existência; b) o de maior dificuldade: apresenta-se acidentado, obscuro, inacessível, porém é uma aventura de vida e de fidelidade consigo mesmo.
[...] a dimensão humana é sempre inferior diante da onipotência do nosso desejo. É muito importante não se sentir doente por causa desse tipo de 'impotência': na realidade, somente diante dela é que podemos captar profundamente a nós mesmos. 0 conhecimento dos nossos aspectos mais secretos só é possível no momento do insucesso, que se torna o espelho verdadeiro do nosso ser, a imagem em que reconhecemos os nossos limites (Carotenuto, 1994, p. 200).

O narcisista coloca o outro no lugar do espectador, com a função de assistir à cena do EU, protagonista, para admirá-lo e proporcionar o aplauso.

Numa cultura narcísica, o ego precisa do outro para afirmar sua competência no campo das relações. Tal qual Don Juan, talvez o pioneiro no registro narcísico, o gozo não se dá no momento do encontro com a amante, mas no seu registro como mais uma conquista.

Nessa medida, a relação se sustenta enquanto o outro se mantém espelho mágico que devolve a imagem pretendida e adotada; mas, se a magia do espelho se quebra e altera a imagem desejada, o outro é sumariamente abandonado e, nos casos mais graves, destruído.

Toda organização narcisista da personalidade vive constantemente sob a ameaça da quebra do espelho, o que lhe exige um esforço constante de hipercompensação, para alegria dos diferentes setores de consumo.

A aproximação de Eros é uma ameaça ao controle do sistema de recompensas do narcisista, pois desloca a fonte de prazer para o Outro, expondo uma vulnerabilidade insuportável.

Para o narcisista, o Amor é uma experiência dolorosa, não pelo que ela traz de sofrimento inevitável, mas principalmente por três razões: uma, por ver no Outro algo que lhe falta e deseja; outra, por temer que o Outro ameace a imagem que deseja apresentar, dada a irredutível individualidade desse Outro ao seu desejo; e, por fim, pelo medo do abandono que o lançaria a um estágio pior do que antes da relação, pois a imagem de grandiosidade e de ser especial não poderá ser mantida, já que o Outro preferiu partir.

O sofrimento amoroso do narcisista decorre de assistir, impotente, à ruína das próprias ilusões megalomaníacas, à queda da máscara. Sem seus escudos, o narcisista sente-se desnudo, exposto à própria fragilidade e dependência. 
É justamente a capacidade de aceitar os elementos relegados à sombra, que pode propiciar a reconciliação dessas dimensões com a consciência do ego. Esse trabalho psíquico implicará no redirecionamento da energia de Eros para a vida interna, trazendo a possibilidade de amar a si mesmo e ao Outro, "na alegria e na tristeza, na saúde e na doença, na pobreza e na riqueza".

Do contrário, a história de amor do narcisista será sempre com sua imagem. Só ao perdê-la pelo bater de asas de Eros é que ele poderá experimentar a dimensão amorosa.

\section{Narcisismo como passagem do amor romântico para 0 amor de alteridade}

A ideia que defendemos neste trabalho é a de que Eros e Narciso podem ser apreendidos como elementos de um binômio. Identificá-los como forças anímicas complementares evita o perigo da unilateralidade, sempre nociva para a saúde psíquica e das relações.

O predomínio exclusivo da dimensão narcísica leva a uma surdez relacional. De fato, é comum nas relações contemporâneas não se escutar o outro, a não ser o mínimo para abrir espaço a sua própria fala. Não há interesse genuíno pelo universo do outro, mas uma curiosidade investigativa que visa a avaliar, apenas, se o outro se "encaixa" no lugar previamente reservado, dentro do grandioso projeto pessoal.

Tal atitude faz lembrar a distinção feita por Buber entre relação Eu-Isso e relação Eu-Tu. Na primeira, o sujeito vê o outro como objeto de satisfação de suas necessidades. Na segunda, o sujeito se abre para a singularidade do Outro com o único objetivo do encontro. Estar em relação com o Outro é uma necessidade arquetípica, ou seja, é próprio da natureza humana buscar o encontro.

0 agente dessa busca é Eros, que contém o Princípio Criativo. A essência da criatividade, quer se manifeste nos relacionamentos e no desenvolvimento humanos, quer nas obras criativas, é o Amor.

No entanto, o amor pode ser usado como álibi para apoiar a identidade e o senso de valor pessoal no outro. Trata-se de uma promessa do amor romântico que, se cumprida, pode impedir o pleno desenvolvimento psicológico. Notadamente entre as mulheres, ainda hoje encontramos as que julgam seu valor, e são julgadas, pela capacidade de atrair e manter um parceiro amoroso.

Neste sentido, a etapa narcísica, no plano coletivo e individual, talvez seja necessária para o processo de superação da ideia de fusão trazida pelo amor romântico, em direção ao encontro amoroso de duas individualidades, como adiantou o poeta Rilke: "o amor são duas solidões que se saúdam".

0 valor que se atribui hoje à autossuficiência pode ter função criativa e necessária para que o amor de alteridade se instale: sem precisar do outro para sobreviver em qualquer categoria, nem mesmo como espelho ou espectador, seria possível amá-lo na sua diferença radical, sem senti-la como ameaça.

Permanecer, no entanto, fixado na etapa narcísica também impossibilita o encontro amoroso e aprofunda o vazio estéril. 0 processo de individuação depende do difícil e instável equilíbrio entre os dois polos: individualidade e intimidade.

A fixação narcísica não leva à autossuficiência como ingenuamente se possa acreditar. Leva, na verdade, a uma dependência insuportável do outro como espelho e espectador da grandiosidade do ego.

Narciso deve, sim, amar sua imagem, mas de maneira radical: amar mesmo o reflexo muitas vezes medonho e desagradável que o espelho do outro possa refletir; pois, como afirmava Sartre, "o inferno são os outros", na medida em que não temos poder sobre a impressão que formam sobre nós.

Ao se amar sem restrições, renunciando o desejo de manipular o reflexo que o Outro lhe devolve, o sujeito poderá amar tanto a imagem refletida como o Outro que segura o espelho...

Concluindo, esta era a proposta que queríamos desenvolver neste trabalho: o narcisismo predominante na psique coletiva e individual na atualidade talvez traga em si o elemento de transformação do amor romântico para o amor de alteridade.

É um grande desafio para nós, psicoterapeutas, acompanharmos pacientes com perfil narcisista na transformação que precisam empreender: da defesa de uma imagem sempre em risco de se quebrar para a aceitação de si mesmos, incluindo os aspectos negligenciados e sombrios. Sem se perder no outro, sem se fechar em cavernas inacessíveis.

Mas o encontro que julgamos necessário entre forças anímicas tão poderosas e antagônicas não pode ter suas consequências totalmente previstas. 
Algumas inquietações permanecem: Eros é um deus, Narciso é humano. Pode Narciso suportar a aproximação de Eros sem se destruir? Poderia Eros se humanizar um pouco aceitando ouvir os receios e necessidades de Narciso? Podemos esperar pelo advento de um novo mito?

\section{Referências}

Arantangy, L. R. (2007). 0 anel que tu me deste: 0 casamento no divã. São Paulo: Artemeios.

Bauman, Z. (2004). Amor líquido: Sobre a fragilidade dos laços humanos. Rio de Janeiro: Jorge Zahar.

Capriotti L. (2005). Narciso acha feio o que não é espelho. Recuperado em 8 out. 2008, em http://www. symbolon.com.br/artigos/NARCISOACHAFEIOOQUENAOEESPELHO.htm

Carotenuto, A. (1994). Eros e pathos: Amor e sofrimento. São Paulo: Paulus.

DSM-IV. (2002). Manual diagnóstico e estatístico de transtornos mentais. (Cláudia Dornelles Trad.) Porto Alegre: Dornelles.
Jung, C. G. (1980). Psicologia do inconsciente. 4. ed. Petrópolis: Vozes.

Lipovetsky, G. (2004a). A Era do vazio. São Paulo: Barcarolla.

Lipovetsky, G. (2004b). Os tempos hipermodernos. São Paulo: Barcarolla.

Lipovetsky, G. (2007). A sociedade da decepção. Barueri: Manole.

Monti, M. R. (2008). Contrato narcisista e clínica do vazio. Revista Latinoamericana de Psicopatologia Fundamental, 11(2), 239-253.

Moore, T. (1992). Cuide da alma. São Paulo: Siciliano.

Ovídio. (2003). Metamorfoses. São Paulo: Madras.

Rios, I. C. (2008). 0 amor nos tempos de Narciso. Interface (Botucatu), 12(25), 421-426.

Roth, P. (2001). 0 animal agonizante. São Paulo: Companhia das Letras.

Schwartz-Salant, N. (1995). Narcisismo e transformação do caráter. São Paulo: Cultrix. 
